University of Nebraska - Lincoln

DigitalCommons@University of Nebraska - Lincoln

2015

\title{
Neural network analysis on the effect of heat fluxes on greenhouse gas emissions from anaerobic swine waste treatment lagoon
}

\author{
N. Lovanh \\ J. Loughrin \\ M. Rysz \\ A. I. Quintanar \\ B. T. Oh
}

See next page for additional authors

Follow this and additional works at: https://digitalcommons.unl.edu/natrespapers

Part of the Natural Resources and Conservation Commons, Natural Resources Management and Policy Commons, and the Other Environmental Sciences Commons

Lovanh, N.; Loughrin, J.; Rysz, M.; Quintanar, A. I.; Oh, B. T.; and Mahmood, Rezaul, "Neural network analysis on the effect of heat fluxes on greenhouse gas emissions from anaerobic swine waste treatment lagoon" (2015). Papers in Natural Resources. 1344.

https://digitalcommons.unl.edu/natrespapers/1344

This Article is brought to you for free and open access by the Natural Resources, School of at DigitalCommons@University of Nebraska - Lincoln. It has been accepted for inclusion in Papers in Natural Resources by an authorized administrator of DigitalCommons@University of Nebraska - Lincoln. 


\section{Authors}

N. Lovanh, J. Loughrin, M. Rysz, A. I. Quintanar, B. T. Oh, and Rezaul Mahmood 


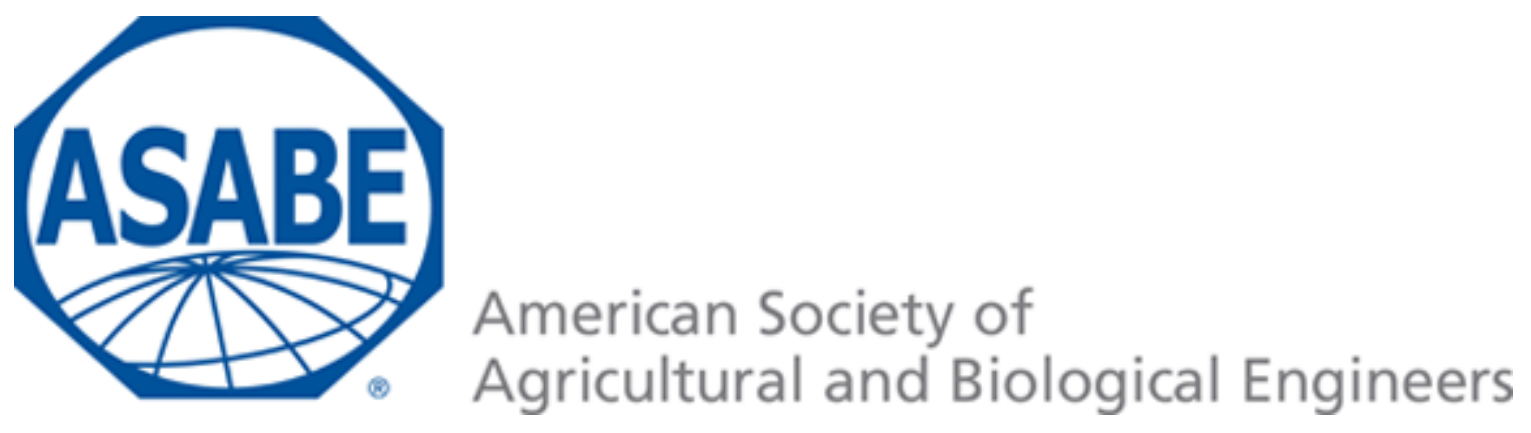

Go Back

\title{
Neural network analysis on the effect of heat fluxes on greenhouse gas emissions from anaerobic swine waste treatment lagoon
}

\author{
N. Lovanh ${ }^{1 *}$, J. Loughrin'1, M. Rysz ${ }^{2}$, A. Quintana ${ }^{3}$, B.T. Oh ${ }^{4}$, and R. \\ Mahmood $^{3}$ \\ ${ }^{1}$ USDA-ARS, AWMRU, Bowling Green, KY 42104 \\ ${ }^{2}$ University of Iowa, Iowa City, IA 52240 \\ ${ }^{3}$ Western Kentucky University, Bowling Green, KY 42104 \\ ${ }^{4}$ Chonbuk National University, Iksan, South Korea
}

This is not a peer-reviewed article.

ASABE 1st Climate Change Symposium: Adaptation and Mitigation, Paper No. 152123798, pages 1-4 (doi: 10.13031/cc.20152123798). St. Joseph, Mich.: ASABE.

\section{Written for presentation at the ASABE 1st Climate Change Symposium: Adaptation and Mitigation Sponsored by ASABE Chicago, Illinois USA May 3 - 5, 2015}

The authors are solely responsible for the content of this meeting presentation. The presentation does not necessarily reflect the official position of the American Society of Agricultural and Biological Engineers (ASABE), and its printing and distribution does not constitute an endorsement of views which may be expressed. Meeting presentations are not subject to the formal peer review process by ASABE editorial committees; therefore, they are not to be presented as refereed publications. Citation of this work should state that it is from an ASABE meeting paper. 
EXAMPLE: Author's Last Name, Initials. 2015. Title of Presentation. ASABE $1^{\text {st }}$ Climate Change Symposium: Adaptation and Mitigation. St. Joseph, Mich.: ASABE. For information about securing permission to reprint or reproduce a meeting presentation, please contact ASABE at publications@asabe.org or 269-932-7004 (2950 Niles Road, St. Joseph, MI 49085-9659 USA).

Abstract. In this study, we examined the various meteorological factors (i.e., air temperatures, solar radiation, and heat fluxes) that potentially affect greenhouse gas (GHG) emissions from swine waste lagoon. GHG concentrations (methane and carbon dioxide) were monitored using a photoacoustic gas analyzer. The GHG emissions from the lagoon were monitored continuously for a twenty-four hour cycle, twice a week during a winter month at a height of fifty centimeters above the lagoon surface. Meteorological data were also monitored simultaneously. Heat fluxes were tabulated and correlated to the averaged GHG concentrations. Multi-layer perceptron (MLP) neural network predictive model was built based on the most important meteorological parameters. The results from MLP neural networks analysis show that GHG emissions from the swine waste lagoon were affected by heat fluxes such as net solar radiation, sensible heat, and latent heat of vaporization. Thus it is important to consider environmental conditions (i.e., meteorological parameters such as solar radiation, latent heat and etc.) in formulating management or abatement strategies for reducing GHG emissions from swine waste lagoons or any other air pollutant emissions from livestock waste receptacles.

Keywords.Climate change

\section{Introduction}

Anaerobic lagoons are effective and low-cost bioreactors to treat animal manure but they are also responsible for emissions of numerous atmospheric pollutants including greenhouse gases (GHGs) and odorous compounds such as skatoles. These pollutants are most prevalent and controlled by the interactions of the atmospheric conditions, biochemical and physical processes occurring at lagoon interfaces. Sulfides and volatile organic compounds (VOCs) such as skatole, cresol, and indole, are thought to be important chemical constituents of offending odors to humans and a cause of discomfort and disease in the environment within and near concentrated animal feeding operations (Cole et al., 2000). Thus, any study on confined animal feeding operations (CAFOs) from swine operations needs to address the issue of anaerobic lagoons as a source of atmospheric pollutants and the potential for devising emission reduction techniques (Loughrin et al., 2006; Lovanh et al., 2009; Loughrin et al., 2011 and 2012). Despite their relatively small size, compared to lakes or estuaries for instance, these lagoons exhibit a considerable amount of complexity when interacting with the atmospheric conditions. This complexity is reflected in the interactions that take place between the atmospheric boundary layer, stratification of the lagoon, and the seasonal changes (Lovanh et al., 2009; Quintanar et al., 2009). Wind stress can drive lagoon surface circulation and stir the upper layers leading to a mixing of solid matter which contributes to the enhancement or reduction of greenhouse gases and VOCs emissions to the atmosphere. Biochemical anaerobic reactions are a key element to the production of above mentioned compounds. The biochemical processes can produce enough internal thermal energy and temperature gradients to modify the lagoon's vertical temperature profiles through heat diffusion and convective motion. Therefore, any study aiming at mitigating its impact on atmospheric pollution needs to clarify the effect of heat fluxes on the production of these pollutants.

\section{Materials and Methods}

Meteorological data were collected for the entire month of February over and/or near an anaerobic swine lagoon (65 x $65 \mathrm{~m}$ and $3 \mathrm{~m}$ in depth) which receives wastewater from four swine houses (total 
of 2,000 sows). Only days with mostly clear sky conditions and no precipitation were chosen to be studied in order to improve on net radiation estimates. Measurements were made on two floating stations that carried instrumentation. Each station recorded temperature, relative humidity and wind speed at $0.5 \mathrm{~m}$ and $1.5 \mathrm{~m}$ above the lagoon surface. For this study we have used data from $0.5 \mathrm{~m}$ level. Ammonia emissions were measured $0.5 \mathrm{~m}$ above the lagoon's surface. Measurements from these two stations were used to account for systematic errors and data quality control. To maximize the amount of fetch to around $60 \mathrm{~m}$, the stations were deployed around the center of the lagoon. It is previously stated that the lowest level of thermometer and hygrometer placement was $0.5 \mathrm{~m}$ above the water surface. As a result, for our $65 \mathrm{~m}$ x $65 \mathrm{~m}$ lagoon, this provides 60:1 for the shortest and about 90:1 for the longest fetch-to-height ratio. For a variety of conditions of fetch-to-height ratios, Stannard (1997; Figure 2d) has shown that ratio of 60:1 can give a Bowen ratio that is about $80 \%$ equilibrated. In this data collection and research effort we used the Stannard (1997) criteria. This criterion was also successfully applied by the authors to similar research studies (Loughrin et al., 2011; Quintanar et al., 2009, 2011).

Included in the meteorological measurements were lagoon surface temperature and subsurface $(0.3$, 0.6, $1.0 \mathrm{~m}$ and lagoon bottom) temperature measurements. GHG emissions were monitored using a Photoacoustic Gas Analyzer (Innova model 1412, Innova Air Tech Instruments A/S, Denmark). The Innova 1412 multi-gas analyzer used a 1-second sampling integration time and fixed flushing time: 2 seconds for the chamber and 3 seconds for the tubing. The required time to complete one sampling cycle was approximately 70 seconds. The response time of the analyzer to step changes in gas emissions was tested. Greenhouse gas emissions were monitored at $0.5 \mathrm{~m}$ above the lagoon surface (to match meteorological measurements). The gas analyzer was housed in a trailer near the lagoon. Gas measurements and meteorological data were collected every 5 minutes.

The theory of neural networks (NNs) computing was first introduced by McCullogh et al. (1943) and further developed by Rosenblatt (1962). The development of NNs was inspired by the learning process of the human brain. NNs usually involve neurons receiving input information, neurons in a hidden layer that pass the information along to other neurons, and neurons that output the processed information. The strongly connected network of neurons captures a global coherent behavior of the phenomena of interest (Robert et al., 1998). NNs are commonly used for classification, pattern recognition, decision making, knowledge data bases for stochastic information, optimization computations, and robot control (Kohonen, 1988).

Data is initially introduced into the network through a set of input nodes. Input variables are weighted and their sum is transformed by a transfer function at the each neuron in the hidden layers. Although transfer functions can be categorized in linear, threshold, and Sigmoidal, the most commonly used are the Sigmoidal functions because they introduce nonlinearity to the problem. Outputs from neurons at one layer become the input for neurons at the consecutive layer. This process continues until the final information is passed through to the output layer. Thus the objective of this study was to examine the effect of photochemical processes such as heat fluxes on the GHGs emission profile from an anaerobic swine lagoon using artificial neural networks (NNs) as a case study for adopting better management strategies and designing alternative remediation options.

\section{Results and Discussion}

The data used in this study were obtained from a swine waste lagoon at a farrowing farm containing approximately 2,000 sows located in Logan County in South Central Kentucky. Greenhouse gas concentrations at the surface of the lagoon along with meteorological data surrounding the lagoon were obtained and analyzed for a one month period (February). These parameters consisted of air temperatures above the lagoon (temperatures at $1.5 \mathrm{~m}, 0.5 \mathrm{~m}$, and surface of lagoon), $\mathrm{pH}$ (6.8 to 7.4), moisture, pressure, wind speeds, and relative humidity. The analysis was completed for clear 
day conditions using time series of hourly meteorological variables for the 28-day in February. Median temperatures vary between 5 and $6{ }^{\circ} \mathrm{C}$ early in the morning ( 2 am local time) and later in the evening ( $8 \mathrm{pm}$ local time). The data also show a diurnal maximum of $13{ }^{\circ} \mathrm{C}$. Upper quartiles were about 5 to $8{ }^{\circ} \mathrm{C}$ above median values while lower quartiles were about 5 to $7^{\circ} \mathrm{C}$ smaller and follow a diurnal cycle as well. The data show a wide range of variations as temperatures fluctuated between -10 to $20^{\circ} \mathrm{C}$. Similar time series for air temperatures from the HOBO station (not shown) exhibited a very similar pattern except that temperatures at $0.5 \mathrm{~m}$ were slightly higher.

Although there were few parameters obtained for this study, most of these were used to tabulate heat fluxes based on Bowen Ratio method (Bowen, 1926; Stull, 1988). In order to determine inconspicuous relationships between potential NN input parameters (see Table 1) in relation to the target GHGs concentration levels we remove parameters which exhibit Pearson's correlation coefficients greater or equal to 0.9 with respect to the target variable. In this regard, only $1.5 \mathrm{~m}$ $\left(\mathrm{T}_{1.5}\right)$ was eliminated from the data set as its respective correlation coefficient exceeded 0.99. Native parameter ranking algorithms in the STATISTICA 7.0 software package (Statsoft, Tulsa, $\mathrm{OK}$ ) were then used to indicate which NN input parameters were the most "influential" on GHGs levels. Several additional parameter selection algorithms such as K-predictors in STATISTICA and sequential-forward selection in WEKA 3.6 were also implemented. However, the best NN model performances resulted by using the five highest ranking parameters under the Boosting Tree (Freund et al., 2003) and Random Forest (Stoppiglia et al., 2003) algorithms in STATISTICA 7.0. Based on the rankings shown the last two columns of Table 1, Surface Temp $\left(\mathrm{T}_{\mathrm{s}}\right)$, Temp at $0.5 \mathrm{~m}\left(\mathrm{~T}_{0.5}\right)$, Net Radiation $\left(\mathrm{R}_{\mathrm{n}}\right)$, Sensible Heat $(\mathrm{H})$ and Latent Heat $(\mathrm{L})$ were deemed important in predicting GHGs emissions from swine waste lagoon, and therefore selected as input variables for our NN models.

Table 1: Input variables ranking.

\begin{tabular}{|l|c|c|c|}
\hline Variable & K-predictors (F-value) & BoostingTree (Rank) & Random Forest (Rank) \\
\hline Surface Temp $\left(\mathrm{T}_{\mathrm{s}}\right)$ & 25.93 & 92 & 79 \\
\hline Temp at $0.5 \mathrm{~m}\left(\mathrm{~T}_{0.5}\right)$ & 45.78 & 100 & 100 \\
\hline Temp at $1.5 \mathrm{~m}\left(\mathrm{~T}_{1.5}\right)$ & 1.26 & 31 & 29 \\
\hline Net Radiation $\left(\mathrm{R}_{\mathrm{n}}\right)$ & 9.62 & 75 & 87 \\
\hline Lagoon Heating $(\mathrm{G})$ & 11.38 & 44 & 42 \\
\hline Sensible Heat $(\mathrm{H})$ & 4.29 & 72 & 52 \\
\hline \hline Latent Heat $(\mathrm{L})$ & 15.29 & 85 & 63 \\
\hline $\mathrm{R}_{\mathrm{n}}-\mathrm{G}$ & 2.58 & 41 & 33 \\
\hline
\end{tabular}

The dataset from Table 1 consisted of 305 measured instances which correlated with the GHGs concentrations. The $75 \%$ and $25 \%$ of the measurements were respectively used to train and test the multi-layer perceptron (MLP) neural network models. In all, 1000 single hidden-layer neural networks were trained. The number of neurons in the hidden layer varied from 3 to 15 . The Broyden-Fletcher-Goldfarb-Shanno (BFGS) algorithm was used to minimize sum of squared error (SSE) - which measures the MLP neural network accuracy - while building each neural network model (Bonnans et al., 2006). Multiple non-linear hidden and output activation functions, including identity, logistic, tanh, and exponential, were used over the hidden and output neurons (not shown). The MLP neural networks successfully identify the non-linear relationship between the process variables as demonstrated with the low training errors. The iteration number of the BFGS algorithm 
ranged between 86 and 241. Based on the native training and test errors, it appears that the MLP neural network with 11 hidden neurons (MLP 5-11-1) performed best with the selected input variables and an exponential output activation function for predicting the effects of heat fluxes on methane. For carbon dioxide, the MLP neural network with 3 hidden neurons (MLP 5-3-1) performed the best prediction. Figures 1 and 2 show the normalized observed values in the test data set versus the corresponding MLP predicted values of methane and carbon dioxide emissions from swine waste lagoon, respectively. Besides the temperature input variables, the various heat fluxes appear to have a major effect on simulating the greenhouse gas emissions from swine lagoon. Most GHGs emission patterns (the highs and lows) were clearly recognized by the model with a few exceptions of extreme high experimental observed values. A reason for the discrepancy may have been because of noise in the data sampled.

[please see the pdf file for figures 1 and 2]

\section{Summary}

Artificial neural network analyses were carried out to examine the effect of heat fluxes on the emission of greenhouse gas emissions (mainly methane and carbon dioxide) from a swine waste lagoon. Based on the results, incorporating various heat fluxes such as net solar radiation, sensible heat, and latent heat of vaporization improves the accuracy of the Multi-layer Perceptron (MLP) neural networks predictive model on GHGs emissions. Therefore, it could be concluded that heat fluxes do affect the emission of greenhouse gases from swine lagoon. Thus it is important to consider environmental conditions (i.e., meteorological parameters such as solar radiation, latent heat and etc.) in formulating management or abatement strategies for reducing GHGs emissions from swine waste lagoons or any other air pollutant emissions from livestock waste receptacles.

\section{Acknowledgements}

We would like to thank Mike Bryant and Marty Haley for their technical assistance. This research was part of USDA-ARS National Program 206: Manure and By-product Utilization. Mention of a trademark or product anywhere in this paper is to describe experimental procedures and does not constitute a guarantee or warranty of the product by the USDA and does not imply its approval to the exclusion of other products or vendors that may also be suitable.

\section{References}

Bonnans, J.F., J.C. Gilbert, C. Lemarechal, and C.A. Sagastizabal. 2006. Numerical Optimization: Theoretical and Practical Aspects. Springer, New York.

Bowen, I.S. 1926. The ratio of heat losses by conduction and evaporation from any water surface. Phy. Rev.27 (6): 779-787.

Cole, D., F. Todd, and S. Wing. 2000. Concentrated swine feeding operations and public health: A review of occupational and community health effects. Environ. Health Perspect. 108(8): 685-699.

Kohonen, T. 1988. An introduction to neural computing. Neural Networks 1(1):3-16.

Loughrin, J.H., A. I. Quintanar, N. Lovanh, R. Mahmood. 2011. Heat flux measurements and

modeling of malodorous compounds above an anaerobic swine lagoon. Water Air Soil Poll. 217 (14): 463-471. 
Loughrin, J. H, A. I. Quintanar, K. L. Cook, N. C.Lovanh, R. Mahmood, and E. Becerra-Acosta 2012. Seasonal Variation in heat fluxes, predicted emissions of malodorants, and wastewater quality of an anaerobic swine waste lagoon. Water Air Soil Poll.

DOI:10.1007/s11270-012-1134-4.

Loughrin, J. H., A. A. Szogi, and M. B. Vanotti.2006. Reduction of malodorous compounds

from a treated swine anaerobic lagoon. J. Env. Quality 35 (1): 194-199.

Lovanh, N., J. H. Loughrin, K. Cook, M. Rothrock, and K. Sistani. 2009. The effect of stratification and seasonal variability on the profile of an anaerobic swine waste treatment lagoon. Bioresour. Tech. 100 (15): 3706-3712.

McCulloch, W. and W. Pitts. 1943. A Logical Calculus of Ideas Immanent in Nervous Activity. Bulletin of Mathematical Biophysics 5:115-133.

Quintanar, A. I., R. Mahmood, J. Loughrin, N. C. Lovanh, and M. V. Motley. 2009. A system for estimating Bowen Ratio and evaporation from waste lagoons. Appl. Eng. Agric. 25(6): 923-932.

Quintanar, A. I., W. Rodgers, R. Mahmood, J. H. Loughrin, and N. Lovanh. 2011. Energy flux comparisons in the surface layer of a waste lagoon during warm and cool season clear skies. Meteorogical Applications (accepted).

Robert C, Guilpin C, Limoge A. 1998. Review of neural network applications in sleep research. J Neurosci Methods 79:187-193.

Rosenblatt, F. 1962. Principles of Neurodynamics: Perceptrons and the Theory of Brain Mechanisms. Spartan Books, Washington DC.

Stull, R.B., 1988. An introduction to boundary layer meteorology. Norwell, MA: Kluwer Academic Publishers.

\section{American Society of Agricultural and Biological Engineers}

